\title{
Total RNA and genomic DNA of Lactobacillus gasseri OLL2809 induce interleukin-12 production in the mouse macrophage cell line J774.1 via toll-like receptors 7 and 9
}

\author{
Kazumasa Onishi, Junko Mochizuki, Asako Sato, Ayako Goto and Toshihiro Sashihara* (D)
}

\begin{abstract}
Background: Lactobacillus gasseri OLL2809 can highly induce interleukin (IL)-12 production in immune cells. Even though beneficial properties of this strain for both humans and animals have been reported, the mechanism by which the bacteria induces the production of IL-12 in immune cells remains elusive. In this study, we investigated the mechanism of induction of IL-12 using a mouse macrophage cell line J774.1.

Results: Inhibition of phagocytosis of L. gasseri OLL2809, and myeloid differentiation factor 88 and Toll-like receptors (TLRs) 7 and 9 signalling attenuated IL-12 production in J774.1 cells. Total RNA and genomic DNA of L. gasseri OLL2809, when transferred to the J774.1 cells, also induced IL-12 production. The difference in the IL-12inducing activity of Lactobacilli is attributed to the susceptibility to phagocytosis, but not to a difference in the total RNA and genomic DNA of each strain.

Conclusion: We concluded that total RNA and genomic DNA of phagocytosed L. gasseri OLL2809 induce IL-12 production in J774.1 cell via TLRs 7 and 9, and the high IL-12-inducing activity of L. gasseri OLL2809 is due to its greater susceptibility to phagocytosis.
\end{abstract}

Keywords: Lactobacillus gasseri OLL2809, IL-12, Phagocytosis, Total RNA, Genomic DNA

\section{Background}

The health benefits of ingesting lactic acid bacteria in humans and animals are well known, and the protective effects of these bacteria in the intestinal environment [1] and in the context of allergy [2], hay fever [3], and obesity $[4,5]$ have also been reported. Some functional lactic acid bacteria are recognized as immunostimulants to the host immune cells, and confer the latter with high cytokine-inducing ability [6-8]. Further detailed studies

\footnotetext{
* Correspondence: toshihiro.sashihara@meiji.com

Food Microbiology Research Laboratories, R\&D Division, Meiji Co., Ltd., 1-29-1 Nanakuni, Hachiouji, Tokyo 192-0919, Japan
}

have reported immune cells to recognize cell wall components [9] and nucleic acids [10-12] of some immunostimulant lactic acid bacteria via Toll-like receptors (TLRs), resulting in cytokine production. However, in many other functional lactic acid bacteria, the cytokineinducing mechanism remains unclear.

Lactobacillus gasseri OLL2809 exhibits high interleukin (IL)-12-inducing ability [13]. IL-12 is a cytokine known to activate natural killer (NK) cells and induce the differentiation of naive $\mathrm{T}$ cells into T-helper 1 cells [14], thereby playing a vital role in the immune reaction. We have reported that L. gasseri OLL2809 exerts several

C C The Author(s). 2020 Open Access This article is licensed under a Creative Commons Attribution 4.0 International License, which permits use, sharing, adaptation, distribution and reproduction in any medium or format, as long as you give appropriate credit to the original author(s) and the source, provide a link to the Creative Commons licence, and indicate if changes were made. The images or other third party material in this article are included in the article's Creative Commons licence, unless indicated otherwise in a credit line to the material. If material is not included in the article's Creative Commons licence and your intended use is not permitted by statutory regulation or exceeds the permitted use, you will need to obtain permission directly from the copyright holder. To view a copy of this licence, visit http://creativecommons.org/licenses/by/4.0/ The Creative Commons Public Domain Dedication waiver (http://creativecommons.org/publicdomain/zero/1.0/) applies to the data made available in this article, unless otherwise stated in a credit line to the data. 
immune-related effects on allergy [15, 16], endometriosis [17], NK activity after high-intensity exercise, and stress loading [18]. However, its IL-12-inducing mechanism in antigen-presenting cells such as macrophages has not yet been elucidated. In this study, we investigated the IL12-inducing mechanism of L. gasseri OLL2809 in the murine macrophage J774.1 cell line addressing the question of the factors affecting the ability of lactic acid bacteria to induce cytokine production.

\section{Results}

\section{Phagocytosis of L. gasseri OLL2809 by J774.1 cells}

There have been several reports indicating that phagocytosis of lactic acid bacteria is required for initiation of IL-12 production from macrophages [9-11]. We first conducted a confocal microscopic analysis to clarify whether phagocytosis of L. gasseri OLL2809 by J774.1 cells is involved in an IL-12 production assay. It has been reported previously that stimulation of IL-12 production from J774.1 cells is more stable or even enhanced in heat-killed bacterial cells rather than live cells [13, 19]; therefore, heat-killed bacterial cells were used in the present study to eliminate the possible influence of probiotic properties such as viability or colonization of the live bacterial cells in the J774.1 culture. The results showed that the FITC-labelled L. gasseri OLL2809 were localized inside but not on the surface of several J774.1 cells (Fig. 1). A further flow cytometric analysis showed that about $30 \%$ of J774.1 cells were FITC positive. Considering the confocal microscopic observations and that flow cytometric analysis was performed after washing the J774.1 cells after labelling to remove excess dye and possible cell surface-attached, FITC-labeled
L. gasseri OLL2809, these FITC-positive J774.1 cells are thought to be those that phagocytosed L. gasseri OLL2809.

\section{Phagocytosis of L. gasseri OLL2809 and IL-12 production by CyD-treated J774.1 cells}

Cell wall components and nucleic acids of lactic acid bacteria act as immunostimulants [9-12, 20], and the pattern-recognition receptors (PRRs) of immune cells that induce cytokines could be expressed both on the cell surface or inside the cells. Lipopolysaccharide (LPS), a ligand of gram-negative bacteria for cell-surfaceexpressed TLR4, stimulates IL-12 production without being phagocytosed [11]. On the other hand, several gram-positive bacterial cell wall components such as peptidoglycan, a ligand for cell-surface expressed TLR2, are also involved in the induction of IL-12 production from macrophages $[21,22]$. To clarify whether stimulation of IL-12 production occurs without phagocytosis via cell-surface expressed PRRs or after phagocytosis followed by recognition of the immunostimulatory component of $L$. gasseri OLL2809 by intracellular PRRs, IL-12 production assay was performed after inhibition of phagocytosis using CyD. Stimulation of IL-12 production was inhibited by CyD in a concentration-dependent manner concomitant with a decrease in phagocytosis of the FITC-labelled L. gasseri OLL2809, as revealed by flow cytometry (Fig. 2a, b). Here, CyD treatment at $2.5 \mu \mathrm{M}$ did not affect the cytotoxicity of the J774.1 cells as well as IL-12 production when stimulated with Pam3CSK4 [23], a synthetic bacterial lipopeptide and a known TLR2-TLR1 ligand (Figure A1). It is therefore suggested that receptors that recognize the components (a)

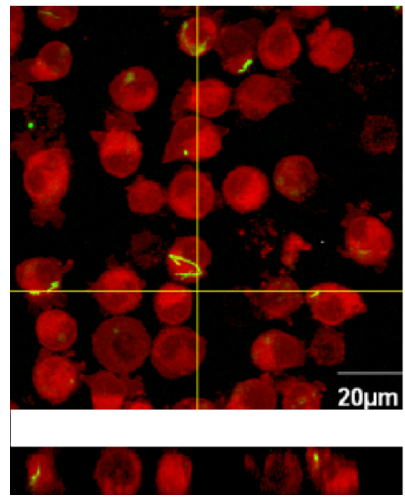

(b)
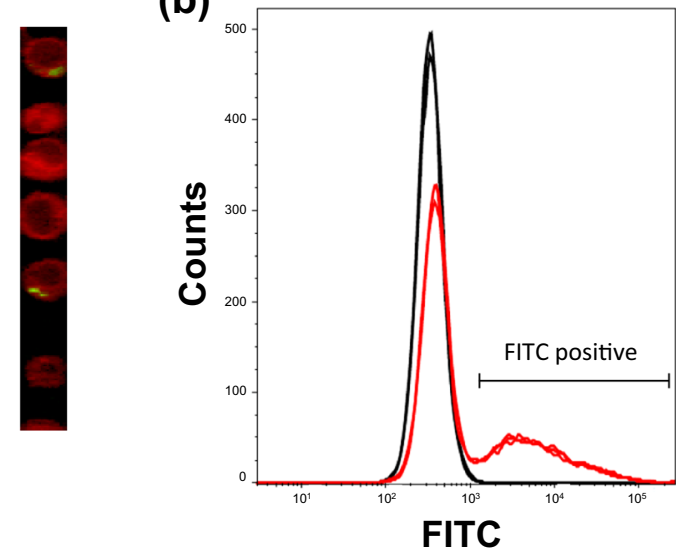

Fig. 1 Confocal microscopic observation (a) and flow cytometric analysis (b) of J774.1 cells that phagocytosed L. gasseri OLL2809. After cultivation for $24 \mathrm{~h}$ in the presence of fluorescein-4-isothiocyanate (FITC)-labelled L. gasseri OLL2809 (green), J774.1 cells were labelled with Cell Mask ${ }^{\text {TM }}$ Deep Red (red) and observed under a confocal microscope (a). The right and below panel showed $x-z$ and $y-z$ stacks at the yellow lines. After incubation for $48 \mathrm{~h}$ in the absence (black) or in the presence of fluorescein-4-isothiocyanate (FITC)-labelled L. gasseri OLL2809 (red), the J774.1 cells were labelled with allophycocyanin conjugated anti-F4/80 antibody and analysed by flow cytometry (b) 

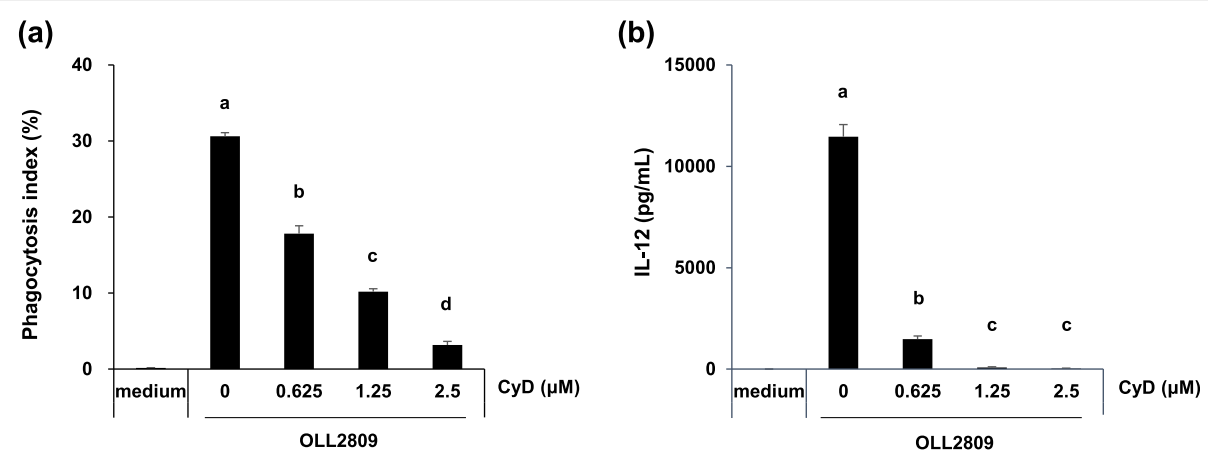

Fig. 2 Effects of cytochalasin D treatment on phagocytosis and IL-12 production in J774.1 cells. J774.1 cells were pre-treated with cytochalasin D (CyD) for $1 \mathrm{~h}$, followed by determination of phagocytosis index by flow cytometry (a) and IL-12 production assay (b). Data are expressed as mean with SD $(n=3)$. Difference between multiple groups was analysed by Tukey-Kramer multiple comparison test $(\mathbf{a}, \mathbf{b})$. a-d: different letters denote significant differences between the groups $(p<0.05)$

of L. gasseri OLL2809 and play an important role in IL12 production are localized inside the cells rather than on the cell surface.

\section{TLRs 7 and 9 inhibition}

TLRs are well-known PRRs involved in cytokine production. It is known that TLRs 3, 7, and 9 are expressed in endosomes of immune cells, and that TLR3 signalling is MYD88-independent whereas TLR 7 and 9 signalling is MYD88-dependent [24]. To examine whether these TLRs of J774.1 cells are involved in IL-12 induction by L. gasseri OLL2809, MYD88 signalling pathways were inhibited in the IL-12 production assay. As shown in Fig. 3, the IL-12 concentration in the culture supernatant decreased depending on the concentration of the MYD88 inhibitory peptide, and no IL-12 production was observed when the cells were treated with $200 \mu \mathrm{M}$ of the inhibitory peptide. Here, the viability of J774.1 cells was not affected by MYD88 inhibitory peptide (Figure A2).

When TLRs 7 or 9 were individually inhibited by IRS661 or IRS869, IL-12 production was significantly decreased as compared with control ODN. In addition, when both TLRs 7 and 9 were inhibited simultaneously, IL-12 production decreased to almost the same level as that in the group treated with medium (Fig. 4). Although the cell viability was significantly reduced by addition of $1 \mu \mathrm{g} / \mathrm{mL}$ of L. gasseri OLL2809, inhibition of TLRs 7 and 9 by these peptides was not found to be cytotoxic to J774.1 cells in this experimental condition (Figure A3). These results indicate that both TLRs 7 and 9 play an important role in IL-12 induction in response to L. gasseri OLL2809.

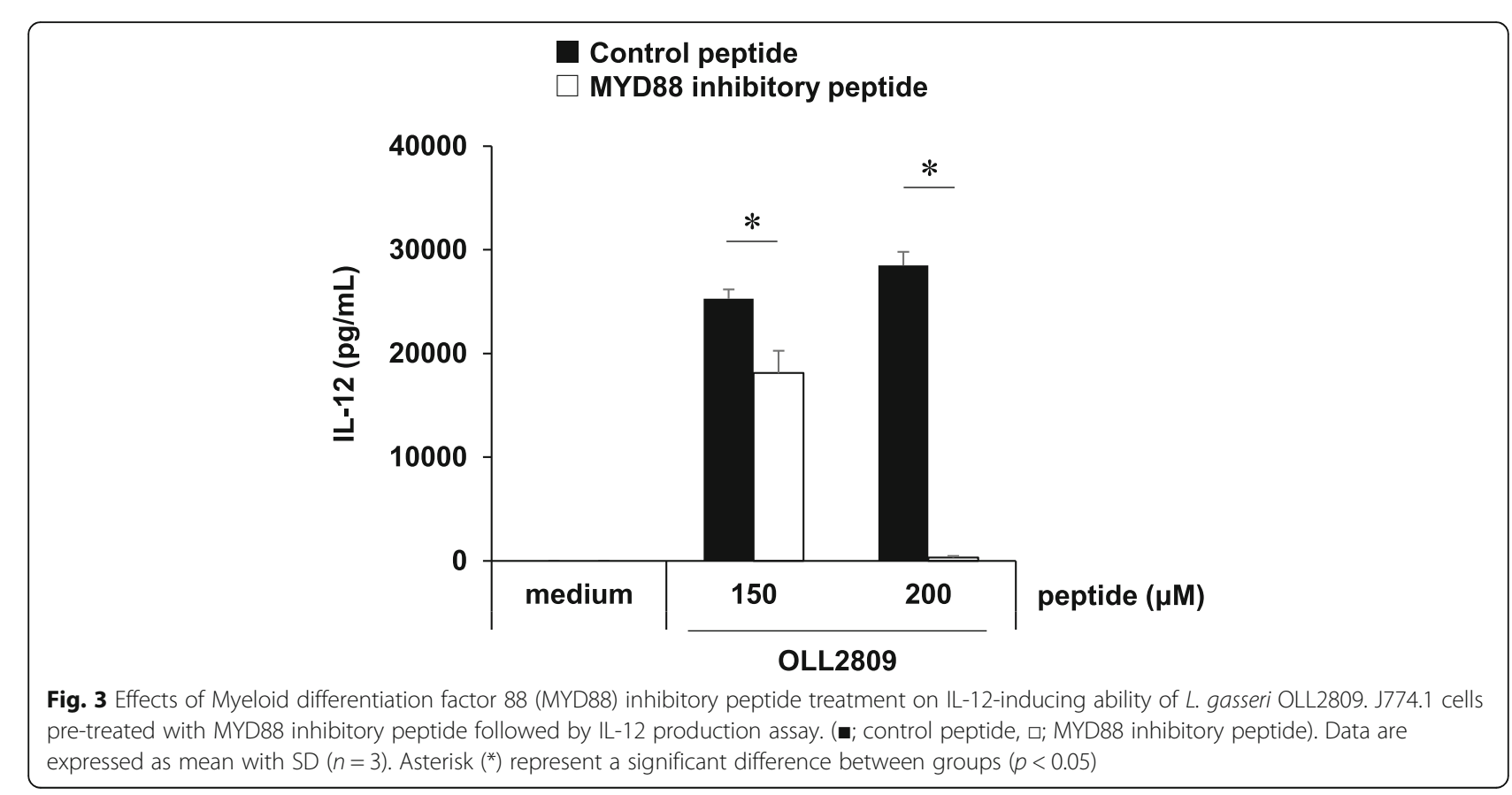




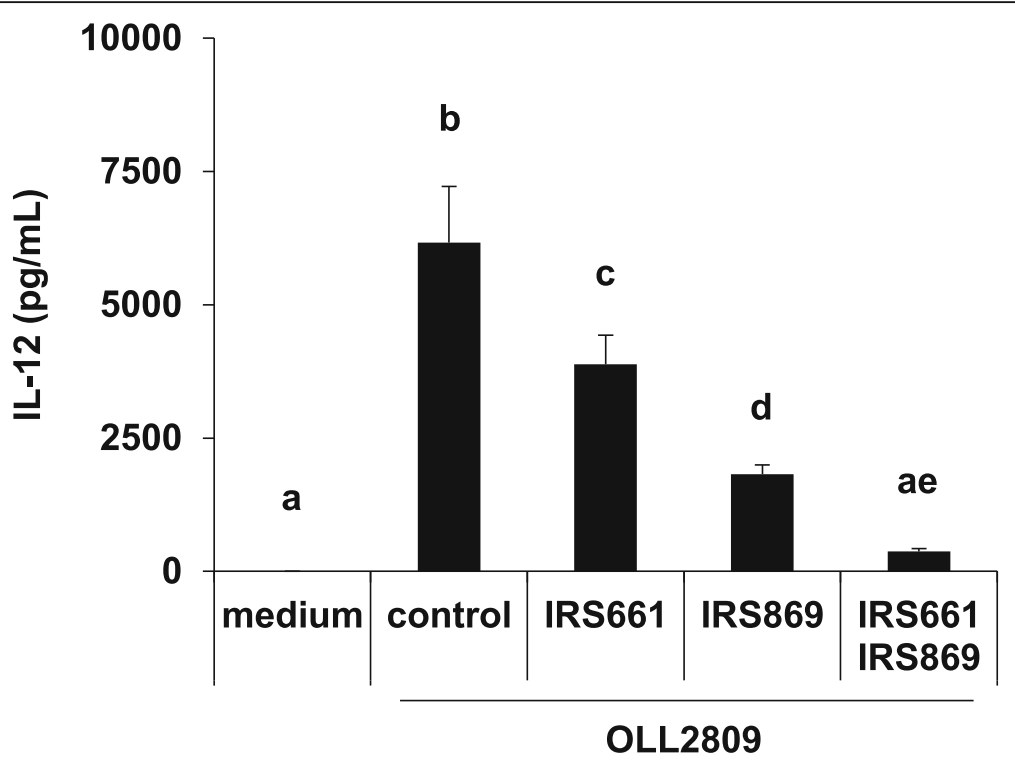

Fig. 4 Effects of Toll-like receptors (TLRs) 7 and 9 antagonist pre-treatment on IL-12 production in J774.1 cells. J774.1 cells were pre-treated with control oligonucleotide (Control), IRS661, IRS869, or both the antagonists for $30 \mathrm{~min}$, followed by IL-12 production assay. Data are expressed as mean with SD $(n=3)$. Difference between multiple groups was analysed by Tukey-Kramer multiple comparison test. a-e: different letters denote significant differences between the groups $(p<0.05)$

\section{IL-12 production by J774.1 cells treated with RNA and} DNA of L. gasseri OLL2809

It is known that the ligands of TLRs 7 and 9 are single-stranded RNA and unmethylated DNA, respectively $[25,26]$. Therefore, IL-12-inducing abilities of total RNA and genomic DNA extracted from L. gasseri OLL2809 were investigated. Both total RNA and genomic DNA of L. gasseri OLL2809 transferred to J774.1 cells with FuGENE induced IL-12 production, although there were significant differences in the intensities among the stimulants (Fig. 5). These effects were not observed without the transfection reagent. These findings suggest that the total RNA and genomic DNA of L. gasseri OLL2809 were recognized by receptors localized inside cells.

Relationship among the phagocytosis index and IL-12 induction ability of Lactobacillus strains, and IL-12inducing abilities of their total RNA and genomic DNA We have reported that immunostimulatory activities are species- and strain-dependent [13]. To examine whether the difference is due to phagocytosis or bacterial cell

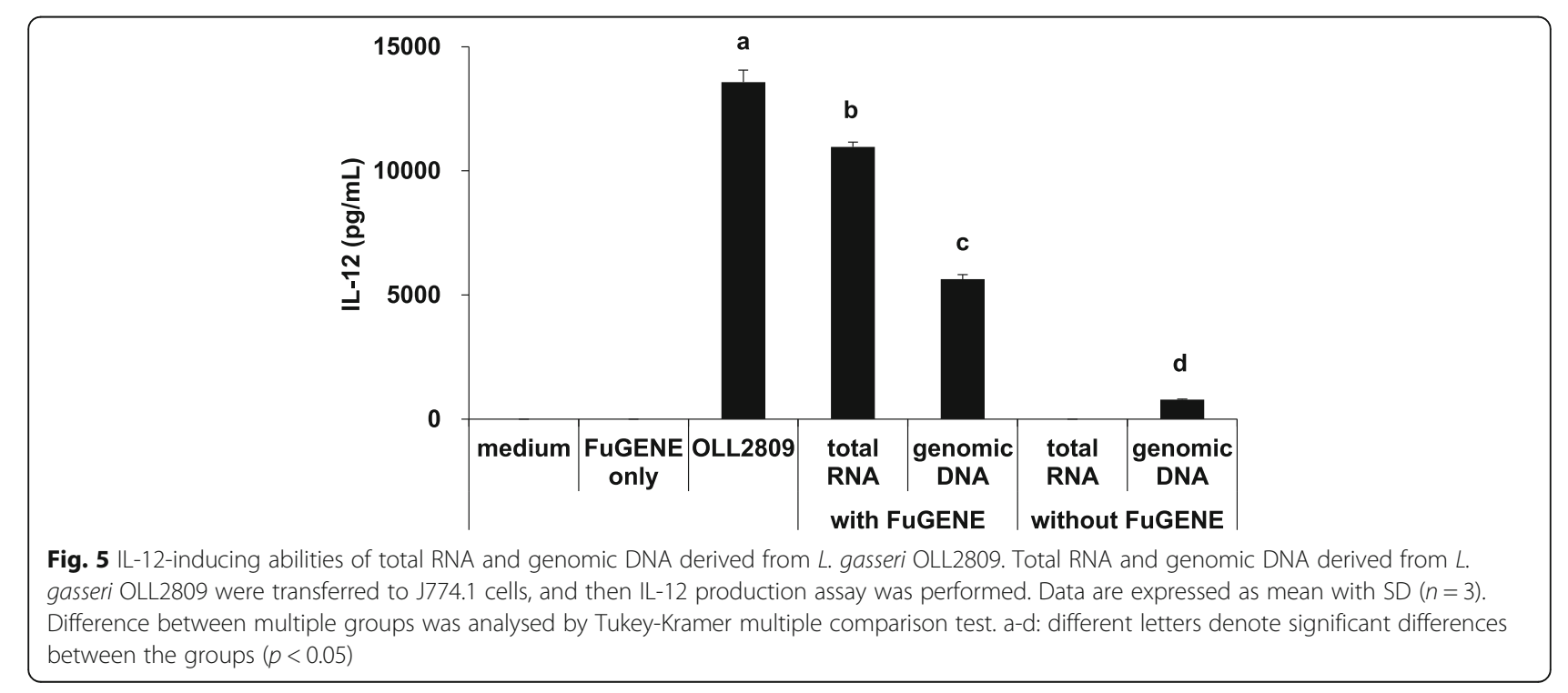


component for TLR signalling, phagocytosis index, and IL12-inducing ability of L. gasseri OLL2809, L. gasseri JCM $1131^{\mathrm{T}}$, L. plantarum JCM $1149^{\mathrm{T}}$ and L. crispatus JCM $1185^{\mathrm{T}}$ were analysed. As shown in Fig. 6, a significant positive correlation was found between phagocytosis index and IL-12-inducing ability (Pearson correlation coefficient; $r=$ $0.0666, n=4, p<0.05)$. Furthermore, in order to evaluate the influence of differences in nucleotide sequences on the IL-12-inducing ability, total RNA and genomic DNA extracted from these lactic acid bacterial cells were transferred to J774.1 cells. The results showed that IL-12 production was substantially induced in all groups including those derived from strains that exhibited less IL-12-inducing activity such as L. plantarum JCM $1149^{\mathrm{T}}$ and $L$. crispatus JCM $1185^{\mathrm{T}}$, although the activity of total RNA extracted from these strains was slightly low but with statistical significance when compared with that of L. gasseri OLL2809 $(p<0.001$, Fig. 7). These data indicate that susceptibility to phagocytosis by J774.1 cells is the most important factor for the IL-12-inducing ability of lactic acid bacteria.

\section{Discussion}

There are roughly two routes by which immune cells recognize microorganisms and induce inflammatory cytokines for self-defence against their infection: recognition by PRRs expressed on the cell surface or by intracellular organs. These receptors, expressed on both the cell surface and inside the cells, play an important role in the recognition of lactic acid bacteria, and the cytokine induction in the immune cells [11]. CyD, a phagocytosis inhibitor, was used to verify whether L. gasseri OLL2809, which was confirmed to be phagocytized (Fig. 1), is recognized by either of the extracellular and intracellular receptors of J774.1 cells. Phagocytosis by J774.1 cells was inhibited by CyD, and IL-12 production was markedly suppressed concomitant with a decrease in phagocytosis of L. gasseri OLL2809 (Fig. 2). This suggested that IL-12 production by J774.1 cells was induced via the receptor expressed on the intracellular organ after phagocytosing $L$. gasseri OLL2809. To investigate whether TLRs, one of the most studied PRRs in immune cells, are involved in the IL-12 induction by L. gasseri OLL2809, we focused on MYD88, an adapter molecule involved in signal transduction by various TLRs. It is known that TLRs 3, 7 , and 9 are expressed in endosomes of immune cells, and that TLR3 signalling is MYD88-independent whereas TLRs 7 and 9 signalling are MYD88-dependent [24]. In our study, inhibition of MYD88 resulted in less production of IL-12 (a)

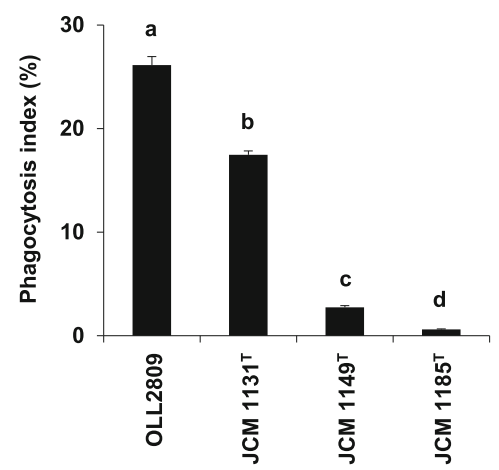

(c)

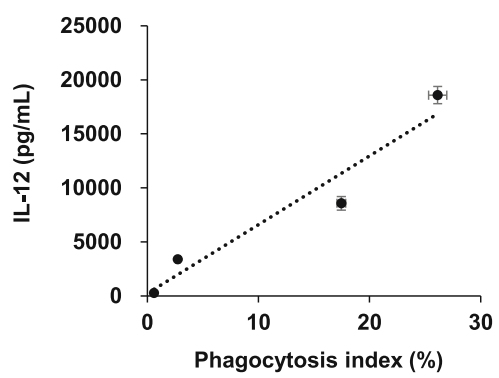

(b)

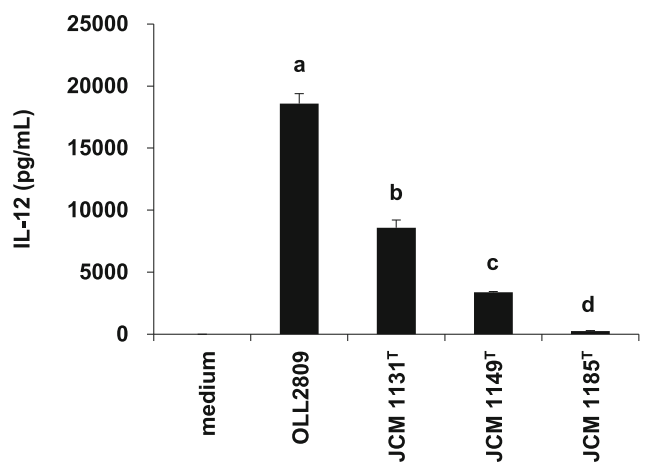

Fig. 6 Relationship between phagocytosis index and IL-12-inducing abilities of various Lactobacilli strains. J774.1 cells were cultivated in the presence of FITC-labelled L. gasseri OLL2809, L. gasseri JCM 1131' ${ }^{\top}$, L. plantarum JCM 1149', and L. crispatus JCM $1185^{\top}$, respectively. After incubation for 48 h, J774.1 cells were labelled with APC conjugated anti-F4/80 antibody and phagocytosis index was analysed by flow cytometry (a). The concentration of IL-12 in the culture supernatant was quantified by ELISA (b). The IL-12 levels and phagocytosis index of each strain are plotted. Pearson correlation coefficient; $r=0.0666, n=4, p<0.05$ (c). Data are expressed as mean with SD $(n=3)$. Difference between multiple groups was analysed by Tukey-Kramer multiple comparison test $(\mathbf{a}, \mathbf{b})$. a-d: different letters denote significant differences between the groups $(p<0.05)$ 


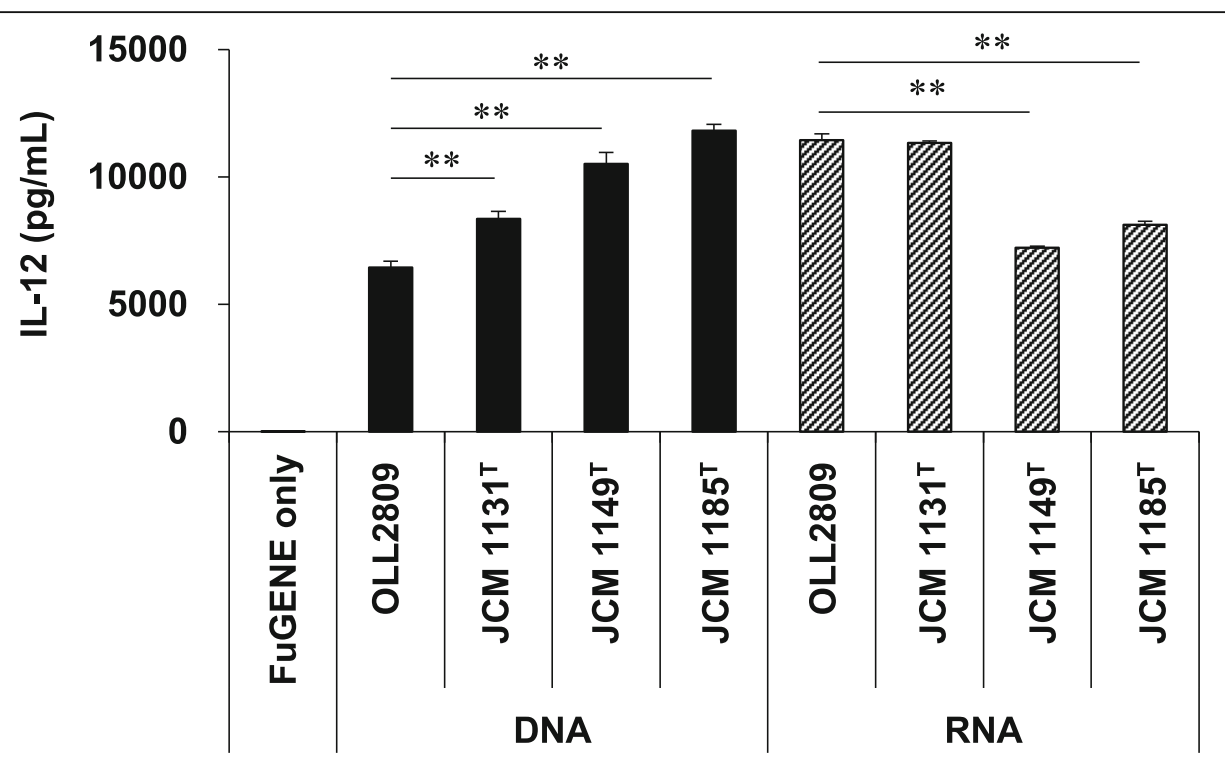

Fig. 7 LL-12-inducing abilities of total RNA and genomic DNA derived from Lactobacilli strains. Total RNA and genomic DNA derived from $L$. gasseri OLL2809, L. gasseri JCM 1131 ${ }^{\top}$, L. plantarum JCM 1149 ${ }^{\top}$, and L. crispatus JCM $1185^{\top}$ were transfected to J774.1 cells using FuGENE, and IL-12 production assay was performed. Data are expressed as mean with SD $(n=3)$. Difference between multiple groups was analysed by Dunnett's multiple comparison test, in which genomic DNA and total RNA were analysed independently. ${ }^{* *}: p<0.01$ vs either of the genomic DNA or total RNA isolated from L. gasseri OLL2809

against L. gasseri OLL2809 stimulation (Fig. 3), suggesting that J774.1 cells recognized components of L. gasseri OLL2809 via TLRs 7 and/or 9 to induce production of IL12. To clarify whether TLRs involved in IL-12 production were either or both of TLRs 7 and 9, antagonists of TLR7 and 9, IRS661 and IRS869, respectively, were used. L. gasseri OLL2809 was added to J 774.1 cells treated with either or both of IRS661 and IRS869. IL-12 production decreased when either TLR 7 or 9 was inhibited, and IL-12 production reduced to almost the same level as that in the control group when both TLRs 7 and 9 were simultaneously inhibited (Fig. 4). These results indicated that both TLRs 7 and 9 play an important role in IL-12 induction in response to L. gasseri OLL2809. It is known that the ligands of TLRs 7 and 9 are single-stranded RNA and unmethylated DNA, respectively $[25,26]$. To further verify whether RNA and DNA of L. gasseri OLL2809 induce IL12 production in J774.1, the IL-12-inducing ability of total RNA and genomic DNA of L. gasseri OLL2809 was examined. IL-12-inducing abilities were observed for both total RNA and genomic DNA of L. gasseri OLL2809 when transferred using a FuGENE system (Fig. 5).

In addition, we clarified a positive correlation between the phagocytosis index and IL-12 inducing-ability using different Lactobacillus strains, i.e., the IL-12-inducing ability was higher in strains more susceptible to phagocytosis (Fig. 6). It was also found that IL-12 production was uniformly induced in J774.1 cells when total RNA or genomic DNA derived from Lactobacillus strains that exhibit less IL-12-inducing activity was transferred (Fig. 7).
In this study, we demonstrated that phagocytosis and the TLR 7 and 9 signalling pathway are involved in the IL-12-inducing mechanism of L. gasseri OLL2809 in J774.1 cells. We further showed that the susceptibility to phagocytosis is highly correlated with the IL-12inducing ability of different lactic acid bacterial strains. Our findings that both genomic DNA and total RNA of various strains exhibited substantial IL-12 inducing ability, although the activities are slightly different in various strains, suggest that phagocytosis is a more crucial factor determining the IL-12 inducing activity of different lactic acid bacterial strains than the actual immune stimulants.

\section{Conclusion}

We concluded that total RNA and genomic DNA of phagocytosed L. gasseri OLL2809 induce IL-12 production in J774.1 cell via TLRs 7 and 9, and the high IL-12inducing activity of L. gasseri OLL2809 is due to its greater susceptibility to phagocytosis. Further studies are required to identify the components of lactic acid bacteria that mediate their phagocytosis by immune cells, and the receptors of the macrophage cells that play an important role in phagocytosis to clarify the mechanism by which different lactic acid bacteria exert different immune-modulatory effects.

\section{Methods}

Bacterial strains and growth conditions

L. gasseri OLL2809 isolated in our laboratory as described previously [13] was cultured in BD Difco ${ }^{\text {тм }}$ 
Lactobacilli MRS Broth (Thermo Fisher Scientific, Waltham, MA, USA) at $37^{\circ} \mathrm{C}$ for $18 \mathrm{~h}$. After fermentation, the bacterial cells were harvested in a refrigerated centrifuge at $10,000 \times g$ for $15 \mathrm{~min}$ and washed twice with saline solution followed by one wash with distilled water. The cells were then resuspended in distilled water, heated at $75^{\circ} \mathrm{C}$ for $1 \mathrm{~h}$, and lyophilized. The lyophilized cells were resuspended in phosphate-buffered saline (PBS; pH 7.4) at a concentration of $200 \mu \mathrm{g} / \mathrm{ml}$ and used for IL-12 production assays.

L. gasseri JCM $1131^{\mathrm{T}}$, L. plantarum JCM $1149^{\mathrm{T}}$ and $L$. crispatus JCM $1185^{\mathrm{T}}$ were purchased from the Riken BRC (Wako, Japan). They were cultured, heat treated and lyophilized as described above.

\section{J774.1 cell culture}

The murine macrophage cell line J774.1 was purchased from the Riken BRC (Wako, Japan). J774.1 cells were cultured in Roswell Park Memorial Institute medium 1640 (RPMI 1640; Thermo Fisher Scientific) supplemented with $10 \%$ fetal bovine serum (FBS; Biosera, Nuaille, France), $100 \mathrm{U} / \mathrm{mL}$ penicillin (Thermo Fisher Scientific), $100 \mu \mathrm{g} / \mathrm{mL}$ streptomycin (Thermo Fisher Scientific) and $55 \mu \mathrm{M}$ 2-mercaptoethanol (Thermo Fisher Scientific) in a humidified $5 \% \mathrm{CO}_{2}$ incubator at $37^{\circ} \mathrm{C}$.

\section{IL-12 production assay}

J774.1 cells were seeded at $5 \times 10^{4}$ cells per $100 \mu \mathrm{L}$ per well in a 96-well plate and cultivated for $48 \mathrm{~h}$ in the absence or presence of $1 \mu \mathrm{g} / \mathrm{ml}$ of the L. gasseri OLL2809. The IL-12 (p40) levels in the culture supernatant were quantified using the mouse IL-12(p40) ELISA set (BD Biosciences, Franklin Lakes, NJ, USA). The same cultivation conditions were used for all experiments, if not otherwise specified.

\section{Fluorescein-4-isothiocyanate (FITC) labelling and confocal microscopy}

Lyophilized L. gasseri OLL2809 (10 mg) were resuspended in $1 \mathrm{~mL}$ of $50 \mathrm{mM}$ carbonate buffer ( $\mathrm{pH}$ 9.6) containing $5 \mu \mathrm{g}$ FITC (Dojindo, Kumamoto, Japan), and incubated at $37^{\circ} \mathrm{C}$ for $1 \mathrm{~h}$. After washing twice with PBS (pH 7.4), the cells were used as FITC-labelled L. gasseri OLL2809. J774.1 cells were cultivated with $2 \mu \mathrm{g} / \mathrm{mL}$ FITC-labelled L. gasseri OLL2809 for $24 \mathrm{~h}$. They were then stained with Cell Mask ${ }^{\text {Tw }}$ Deep Red (Thermo Fisher Scientific) and observed with confocal microscopy (Olympus, Tokyo, Japan).

\section{Flow cytometric analysis}

J774.1 cells were cultivated in the presence of $2 \mu \mathrm{g} / \mathrm{mL}$ FITC-labelled L. gasseri OLL2809 for $48 \mathrm{~h}$. They were then harvested and labelled with allophycocyanin (APC) conjugated anti-F4/80 antibody (Bio-Rad, Hercules, CA,
USA) and 7-amino-actinomycin D (7-AAD; BD Biosciences). The J774.1 cells were washed 2 twice with PBS (pH 7.4) and 7-AAD-negative, FITC-positive and F4/80positive cells were counted on the flow cytometer FACS Verse $^{\mathrm{Tm}}$ (BD Biosciences). The proportion of FITCpositive cells in F4/80-positive cells was defined as phagocytosis index, and that of 7-AAD- positive cells was defined as the dead cell ratio.

\section{Inhibition of phagocytosis, and MYD88 and TLRs 7 and 9 signalling}

For inhibition of phagocytosis and Myeloid differentiation factor 88 (MYD88) and TLR 7 and 9 signalling, J774.1 cells were treated with various reagents followed by IL-12 production assays.

For phagocytosis, J774.1 cells were pre-treated with 0 , $0.625,1.25,2.5 \mu \mathrm{M}$ cytochalasin D (CyD; Fujifilm Wako Pure Chemical, Osaka, Japan) for $1 \mathrm{~h}$. For MYD88 signalling, J774.1 cells were pre-treated with $150,200 \mu \mathrm{M}$ of MYD88 homodimerization inhibitory peptide or the control peptide (Novus Biologicals, Centennial, CO, USA) for $24 \mathrm{~h}$. The culture medium was replenished with fresh media, and then IL-12 production assay was performed. The amino acid sequences of the peptides were as follows;

Control peptide: DRQIKIWFQNRRMKWKK

Inhibitory peptide: DRQIKIWFQNRRMKWKKRDVLP GT

For TLRs 7 and 9, TLR7 antagonist immunoregulatory sequence (IRS)661 [27], and TLR9 antagonist IRS869 [10] as well as the control oligodeoxynucleotide (ODN) [28], were synthesized by Eurofins Genomics (Tokyo, Japan). J774.1 cells were pre-treated with $1 \mu \mathrm{M}$ of IRS661, or IRS869, or both for $30 \mathrm{~min}$. Nucleotide sequences of ODNs were as follows;

Control: TCCTGCAGGTTAAGT

IRS661 (Antagonist of TLR7): TGCTTGCAAGCTTG CAAGCA

IRS869 (Antagonist of TLR9): TCCTGGAGGGGTTGT

\section{Extraction of RNA and DNA from bacterial strains and transfer to J774.1 cells}

Total RNA and genomic DNA were extracted from bacterial strains by using Nucleo Spin ${ }^{\circ}$ RNA (Takara Bio, Shiga, Japan) or Nucleo Spin ${ }^{\circ}$ Microbial DNA (Takara Bio). The concentration of the extracted nucleotides was measured by Nano Drop 1000 (Thermo Fisher Scientific). Further, $5 \mu \mathrm{L}$ of FuGENE ${ }^{\bullet} \mathrm{HD}$ (Promega, Fitchburg, WI, USA) was added to $100 \mu \mathrm{L}$ of Opti-MEM (Thermo Fisher Scientific) containing $2 \mu \mathrm{g}$ of the extracted nucleotide, and the mixtures were incubated for $10 \mathrm{~min}$ at room temperature to form total RNA/ FuGENE or genomic DNA/FuGENE complexes. The total RNA/FuGENE or genomic DNA/FuGENE were 
diluted 20-fold and used to stimulate J774.1 cells for IL12 production assays.

\section{Statistical analyses}

Data are expressed as mean values with standard deviations (SD). Difference between multiple groups was analysed by Tukey-Kramer or Dunnett's multiple comparison test. For analysis of the two groups in the MYD88 signal inhibition experiment, the Student's $t$-test was used. Differences were considered significant when the $p$-values for the effect were less than 0.05 .

\section{Supplementary information}

Supplementary information accompanies this paper at https://doi.org/10. 1186/s12866-020-01900-w.

Additional file 1: Figure A1. Effects of cytochalasin D treatment on viability of J774.1 cells (a) and IL-12 production stimulated with Pam3CSK4. Figure A2. Viability of J774.1 cells during MYD88 inhibition assay. Figure A3. Viability of J774.1 cells during TLRs 7 and 9 antagonist assay. (XLS $294 \mathrm{~kb}$ )

\section{Abbreviations}

IL: Interleukin; TLR: Toll-like receptor; NK: Natural killer; RPMI: Roswell Park Memorial Institute; FBS: Foetal bovine serum; FITC: Fluorescein-4isothyocyanate; PBS: Phosphate-buffered saline; APC: Allophycocyanin; $7-$ AAD: 7-amino-actinomycin D; MYD88: Myeloid differentiation factor 88; CyD: Cytochalasin D; IRS: Immunoregulatory sequence;

ODN: Oligodeoxynucleotide; SD: Standard deviation; PRR: Pattern-recognition receptor; LPS: Lipopolysaccharide

\section{Acknowledgements}

Not applicable.

\section{Authors' contributions}

Conceptualization and design of the work, K.O. and T.S.; the acquisition and analysis, A.S., J.M. A.G., interpretation of data, K.O.; writing —original draft preparation, K.O.; writing-review and editing, T.S.; supervision, T.S. All authors have read and approved the final manuscript.

\section{Funding}

This research received no external funding.

\section{Availability of data and materials}

The data set supporting our results are included within the article.

\section{Ethics approval and consent to participate}

Not applicable.

\section{Consent for publication}

Not applicable.

\section{Competing interests}

The authors declare no competing interests.

Received: 9 February 2020 Accepted: 12 July 2020

Published online: 20 July 2020

\section{References}

1. Perdigon G, Alvarez S, Nadar de Macias ME, Roux ME, de Ruiz Holgado AP. The oral administration of lactic acid bacteria increase the mucosal intestinal immunity in response to enteropathogens. J Food Prot. 1990:53: 404-10

2. Wang MF, Lin $\mathrm{HC}$, Wang $\mathrm{YY}$, Hsu $\mathrm{CH}$. Treatment of perennial allergic rhinitis with lactic acid bacteria. Pediatr Allergy Immunol. 2004;15:152-8.
3. Repa A, Grangette C, Daniel C, Hochreiter R, Hoffmann-Sommergruber K, Thalhamer J, et al. Mucosal co-application of lactic acid bacteria and allergen induces counter-regulatory immune responses in a murine model of birch pollen allergy. Vaccine. 2003;22:87-95.

4. Lee HY, Park JH, Seok SH, Baek MW, Kim DJ, Lee KE, et al. Human originated bacteria, Lactobacillus rhamnosus PL60, produce conjugated linoleic acid and show anti-obesity effects in diet-induced obese mice. Biochim Biophys Acta. 1761;2006:736-44.

5. Toshimitsu T, Ozaki S, Mochizuki J, Furuichi K, Asami Y. Effects of Lactobacillus plantarum strain OLL2712 culture conditions on the antiinflammatory activities for murine immune cells and obese and type 2 diabetic mice. Appl Environ Microbiol. 2017;83:e03001-6.

6. Kato I, Tanaka K, Yokokura T. Lactic acid bacterium potently induces the production of interleukin-12 and interferon- $\gamma$ by mouse splenocytes. Int J Immunopharmacol. 1999;21:121-31.

7. Ongol MP, Iguchi T, Tanaka M, Sone T, Ikeda H, Asano K, et al. Potential of selected strains of lactic acid bacteria to induce a Th1 immune profile. Biosci Biotechnol Biochem. 2008;72:2847-57.

8. Takeda S, Kawahara S, Hidaka M, Yoshida H, Watanabe W, Takeshita M, et al. Effects of oral administration of probiotics from Mongolian dairy products on the Th1 immune response in mice. Biosci Biotechnol Biochem. 2013;77: 1372-8.

9. Kaji R, Kiyoshima-Shibata J, Nagaoka M, Nanno M, Shida K. Bacterial teichoic acids reverse predominant IL-12 production induced by certain Lactobacillus strains into predominant IL-10 production via TLR2-dependent ERK activation in macrophages. J Immunol. 2010;184:3505-13.

10. Hoshino G, Inoue R, Nagino T, Ushida K. Nucleic acids of Enterococcus faecalis strain EC-12 are potent Toll-like receptor 7 and 9 ligands inducing interleukin-12 production from murine splenocytes and murine macrophage cell line J774.1. FEMS Immunol Med Microbiol. 2011;61:94-102.

11. Nakase J, Ukawa Y, Takemoto S, Kubo T, Sagesaka YM, Aoki-Yoshida A, et al. RNA and a cell wall component of Enterococcus faecalis IC-1 are required for phagocytosis and interleukin 12 production by the mouse macrophage cell line J774.1. Biosci Biotechnol Biochem. 2017:81:1099-105.

12. Aoki R, Suzuki C, Kimoto H, Nomura M, Mizumachi K. Lactococcus strains treated with heat and hen-egg-white lysozyme induce abundant interleukin-12 production by $\mathbf{J} 774.1$ macrophages and murine spleen cells. J Dairy Sci. 2011;94:3262-70.

13. Sashihara T, Sueki N, Ikegami S. An analysis of the effectiveness of heat-killed lactic acid bacteria in alleviating allergic diseases. J Dairy Sci. 2006;89:2846-55.

14. Scharton-Kersten T, Afonso LC, Wysocka M, Trinchieri G, Scott P. IL-12 is required for natural killer cell activation and subsequent $T$ helper 1 cell development in experimental leishmaniasis. J Immunol. 1995;154:5320-30.

15. Sashihara T, Ikegami S, Sueki N, Yamaji T, Kino K, Taketomo N, et al. Oral administration of heat-killed Lactobacillus gasseri OLL2809 reduces cedar pollen antigen-induced peritoneal eosinophilia in mice. Allergol Int. 2008;57: 397-403.

16. Gotoh M, Sashihara T, Ikegami S, Yamaji T, Kino K, Orii N, et al. Efficacy of oral administration of a heat-killed Lactobacillus gasseri OLL2809 on patients of Japanese cedar pollinosis with high Japanese-cedar pollen-specific lgE. Biosci Biotechnol Biochem. 2009:73:1971-7.

17. Itoh H, Uchida M, Sashihara T, Ji ZS, Li J, Tang Q, et al. Lactobacillus gasseri OLL2809 is effective especially on the menstrual pain and dysmenorrhea in endometriosis patients: randomized, double-blind, placebo-controlled study. Cytotechnol. 2011;63:153-61.

18. Sashihara T, Nagata M, Mori T, Ikegami S, Gotoh M, Okubo K, et al. Effects of Lactobacillus gasseri OLL2809 and alpha-lactalbumin on university-student athletes: a randomized, double-blind, placebo-controlled clinical trial. Appl Physiol Nutr Metabol. 2013;38:1228-35.

19. Miyazawa K, He F, Kasase M, Kubota A, Yoda K, Hiramatsu M. Enhancement of immunoregulatory effects of Lactobacillus gasseri TMC0356 by heat treatment and culture medium. Lett Appl Microbiol. 2011:53:210-6.

20. Hatano S, Hirose Y, Yamamoto Y, Murosaki S, Yoshikai Y. Scavenger receptor for lipoteichoic acid is involved in the potent ability of Lactobacillus plantarum strain L-137 to stimulate production of interleukin-12p40. Int Immunopharmacol. 2015:25:321-31.

21. Lawrence C, Nauciel C. Production of interleukin-12 by murine macrophages in response to bacterial peptidoglycan. Infect Immun. 1998; 66:4947-9.

22. Aoi N, Morikura I, Fuchiwaki T, Yamada T, Prokopakis E, Kawauchi H. OK-432 administration inhibits murine allergic rhinitis at the induction phase, 
throught the macrophage activation with TLR2 signaling pathway. Med Sci. 2018;6:E107.

23. Aliprantis AO, Yang RB, Mark MR, Suggett S, Devaux B, Radolf JD, et al. Cell activation and apoptosis by bacterial lipoproteins through toll-like receptor2. Science. 1999;285:736-9.

24. Takeda K, Akira S. TLR signaling pathways. Semin Immunol. 2004;16:3-9.

25. Diebold SS, Kaisho T, Hemmi H, Akira S, Reis e Sousa C. Innate antiviral responses by means of TLR7-mediated recognition of single-stranded RNA. Science. 2004;303:1529-31.

26. Hemmi H, Takeuchi O, Kawai T, Kaisho T, Sato S, Sanjo H, et al. A toll-like receptor recognizes bacterial DNA. Nature. 2000;408:740-5.

27. Barrat F, Meeker T, Gregorio J, Chan JH, Uematsu S, Akira S, et al. Nucleic acids of mammalian origin can act as endogenous ligands for toll-like receptors and may promote systemic lupus erythematosus. J Exp Med. 2005;202:1131-9.

28. Pawar RD, Ramanjaneyulu A, Kulkarni OP, Lech M, Segerer S, Anders HJ, et al. Inhibition of toll-like receptor-7 (TLR-7) or TLR-7 plus TLR-9 attenuates glomerulonephritis and lunginjury in experimental lupus. J Am Soci Nephrol. 2007;18:1721-31.

\section{Publisher's Note}

Springer Nature remains neutral with regard to jurisdictional claims in published maps and institutional affiliations.

Ready to submit your research? Choose BMC and benefit from:

- fast, convenient online submission

- thorough peer review by experienced researchers in your field

- rapid publication on acceptance

- support for research data, including large and complex data types

- gold Open Access which fosters wider collaboration and increased citations

- maximum visibility for your research: over $100 \mathrm{M}$ website views per year

At $\mathrm{BMC}$, research is always in progress.

Learn more biomedcentral.com/submissions 